\title{
Taste disorder in facial onset sensory and motor neuronopathy: a case report
}

\author{
Nobuhiko Ohashi ${ }^{1}$, Jin Nonami ${ }^{1}$, Minori Kodaira ${ }^{1 *} \mathbb{D}$, Kunihiro Yoshida ${ }^{2}$ and Yoshiki Sekijima ${ }^{1,3}$
}

\begin{abstract}
Background: Taste disorder is a common symptom in the general population. Several studies have shown that patients with neurological disorders, such as amyotrophic lateral sclerosis and Parkinson's disease, develop taste disturbance. Facial onset sensory and motor neuronopathy (FOSMN) is a rare disease characterized by sensory disturbance and weakness spreading from the face to the limbs caudally. We describe a patient with FOSMN who showed taste disorder as the sole initial symptom.

Case presentation: A 49-year-old man who smoked cigarettes developed taste disturbance. Despite using zinc supplements, an herbal medication, and an ointment, his taste disorder worsened. 4 years later, a tingling feeling emerged at the tip of his tongue and gradually spread to his entire lips. At 55 years of age, he showed difficulty in swallowing, followed by facial paresthesia, muscle atrophy, and weakness in the face and upper limbs without apparent upper motor neuron sign. Cessation of smoking did not improve his taste disturbance, and he was unable to discriminate different tastes on the entire tongue. In an electrogustometric study, electrical stimulation did not induce any type of taste sensation. Blink reflex showed delayed or diminished R2 responses. Needle electromyography revealed severe chronic neurogenic changes in the tongue and masseter muscles. Mild chronic neurogenic changes were also observed in the limbs. In the thoracic paraspinal muscles, active neurogenic changes were detected. Findings of hematological and cerebrospinal fluid analyses, and magnetic resonance images of the brain and spinal cord were unremarkable. One cycle of intravenous immunoglobulin therapy did not improve his symptoms. We diagnosed him as having FOSMN with the sole initial symptom of taste disorder. Nine years after the onset of taste disorder, he developed impaired sensation of touch in the right upper limb and required tube feeding and ventilator support.
\end{abstract}

Conclusion: Taste disorder can be the initial manifestation of FOSMN and might involve the solitary nucleus.

Keywords: Facial onset sensory and motor neuronopathy, Taste disorder, Solitary nucleus

\section{Background}

Taste disorder is among the common symptoms encountered in routine medical practice. Indeed, previous studies have reported that $0.6-20 \%$ of the general population suffer from taste dysfunction [1-5]. The taste sensation can be disturbed by various factors and disorders, such as aging, drug, zinc deficiency, infection, and head surgery [6]. Furthermore, patients with neurological disorders, such as amyotrophic lateral sclerosis (ALS), seizures, and Alzheimer's and Parkinson's diseases, may present with taste disturbance [7-9].

\footnotetext{
* Correspondence: mkodaira@shinshu-u.ac.jp

${ }^{1}$ Department of Medicine (Neurology and Rheumatology), Shinshu University

School of Medicine, Matsumoto, Japan

Full list of author information is available at the end of the article
}

Facial onset sensory and motor neuronopathy (FOSMN) is a rare disease characterized by sensory disturbance and weakness of the face followed by muscle weakness in the limbs [10-12]. FOSMN might be a variant of ALS resulting from an irreversible disease progression with a lack of response to immunotherapies as well as deposition of TAR DNA-binding protein 43 (TDP-43) in the nervous systems [13-15]. However, the clinical pictures and pathophysiology of FOSMN have not been well established. Herein, we report a patient with FOSMN who showed taste disorder as the sole initial symptom of the disease.

(c) The Author(s). 2020 Open Access This article is distributed under the terms of the Creative Commons Attribution 4.0 International License (http://creativecommons.org/licenses/by/4.0/), which permits unrestricted use, distribution, and reproduction in any medium, provided you give appropriate credit to the original author(s) and the source, provide a link to the Creative Commons license, and indicate if changes were made. The Creative Commons Public Domain Dedication waiver (http://creativecommons.org/publicdomain/zero/1.0/) applies to the data made available in this article, unless otherwise stated. 


\section{Case presentation}

The patient was a Japanese man without a significant family history. He was a smoker and had noticed impairment of his sense of smell following a sinusitis surgery at the age of 20 years. He had no history of medication use. At the age of 49 years, he developed taste disturbance with a lingering salty taste in the mouth and tasted barley tea as salty noodle soup. One year later, he visited a local otolaryngology clinic. He was suspected to have zinc deficiency, and oral zinc supplements were administered. However, his taste disturbance progressed to a sweet taste in addition to the salty taste within the month. At the age of 53 years, a tingling feeling emerged at the tip of the tongue and gradually spread to his entire lips. Despite using an herbal medication and an ointment, these abnormal sensations remained. At the age of 55 years, he showed mild difficulty in swallowing. During the following year, he stopped smoking, but it did not improve his taste disturbance. Subsequently, he developed speech difficulties and muscle wasting of the neck and upper limbs and was referred to our hospital. $\mathrm{He}$ presented with mild impairment of the smell sensation. Neither ptosis nor an eye movement disorder was apparent. He showed numbness around the mouth. Touch and pinprick sensations were decreased in the area of the third division of the bilateral trigeminal nerves. Moderate muscle weakness was detected in the orbicularis oculi and oris muscles. Muscle atrophy was noted in the temporal, masseter, and sternocleidomastoid muscles (Fig. 1). He had mild dysarthria with remarkable atrophy and fasciculation of the tongue. Corneal and gag reflexes were absent. Severe weakness of the neck extensors caused his head to drop. Further, mild muscle weakness was detected in the left upper limb. Sensory disturbances in the trunk and limbs were not apparent. Bilateral tendon reflexes were normal in the upper limbs and slightly brisk in the lower limbs without pathological reflexes. Neither cerebellar ataxia nor dysautonomia was apparent. Hematological analysis revealed mild elevation of creatinine kinase (392 U/l). Results of complete blood

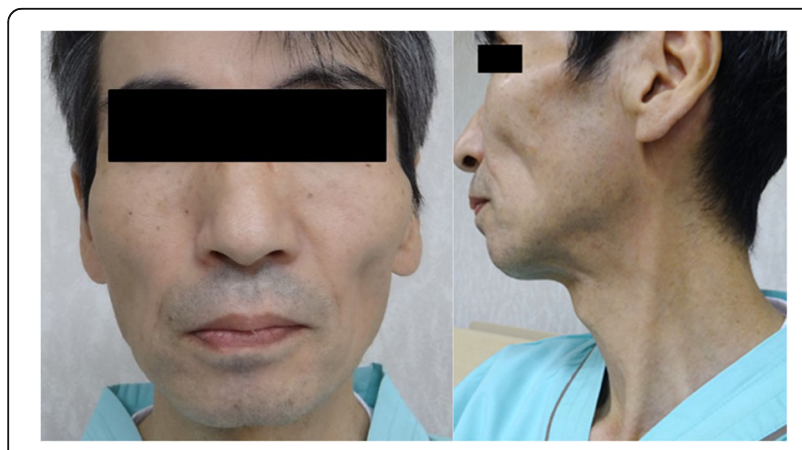

Fig. 1 Atrophy of the temporal, masseter, and sternocleidomastoid muscles count; electrolytes, including sodium and zinc; vitamin B1 and B12; total cholesterol and triglyceride; blood sugar and $\mathrm{HbA1c}$; liver and renal functions; autoantibodies including anti-SS-A and SS-B, anti-GM1, and GQ1b IgG; and C-reactive protein were normal. Cerebrospinal fluid analysis revealed unremarkable findings. Magnetic resonance imaging (MRI) of the brain was unremarkable. MRI of the spinal cord showed mild cervical spondylosis without spinal cord atrophy. Pulmonary function test showed mild decrement of \% vital capacity (76.4\%). Results of a nerve conduction study were normal except for reduced F-wave occurrence in the median nerve (30\%). In needle electromyography, chronic neurogenic changes with severely decreased number of motor units and high amplitude/long duration motor unit potentials were apparent in the tongue and masseter muscles. Mild chronic neurogenic changes were also observed in the biceps brachii, first dorsal interosseous, quadriceps, and gastrocnemius medialis muscles. Active neurogenic changes, including fasciculation potentials were unapparent in these muscles. In the thoracic paraspinal muscles, fibrillation potentials and positive sharp waves were detected. Regarding the blink reflex, both sides of the R2 components after ipsilateral stimulation were delayed, while the right side of the R2 component after left stimulation was absent (Fig. 2). An assessment using the disc test revealed that the patient was unable to discriminate different tastes in the entire tongue. In an electrogustometric study, electrical stimulation of all segments of the tongue failed to induce any type of taste sensation. Laryngoscopy showed no evidence of inflammation and/or masses within the larynx and pharynx. One session of intravenous immunoglobulin (IVIG) therapy $(2 \mathrm{~g} / \mathrm{kg}$ body weight over 5 days $)$ did not improve any of his symptoms and signs. Based on these results, we diagnosed him as having FOSMN with the sole initial symptom of taste disorder. Nine years after the onset of the condition, he developed impaired sensation of touch in the right upper limb and required mechanical ventilation and nutritional support via tube feeding. Subsequent electromyography studies were not performed.

\section{Discussion}

FOSMN is characterized by an initial manifestation of somatosensory sensory disturbance and/or weakness in the face; however, our patient developed taste disorder as the initial symptom. Smoking may have facilitated the onset and progression of taste disorder in our patient, but subjects with chronic exposure to cigarette smoke can experience improved taste disturbance soon after the cessation of smoking [17]. Thus, we think that taste disorder in our patient was associated with FOSMN. 
Right stimulation

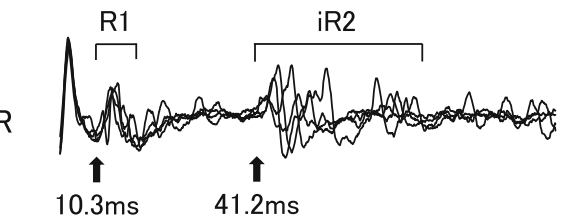

Left stimulation
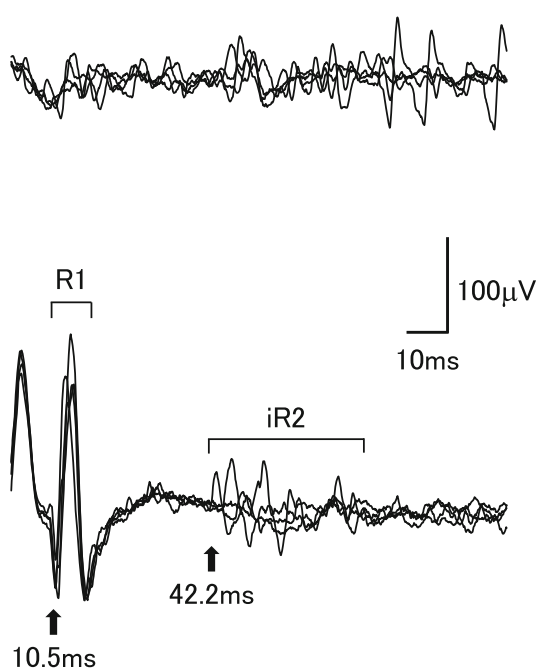

Fig. 2 Evaluation of the blink reflex. The blink reflex shows impaired brainstem function with delayed or absent R2 responses after ipsilateral and contralateral stimulation. Arrows indicate latency of each response. Normal values (ms): R1 $10.5 \pm 0.8$, ipsilateral R2 (iR2) $30.5 \pm 3.4$, and contralateral R2 (cR2) $30.5 \pm 4.4$ [16]

Table 1 Clinical features in FOSMN patients with a taste disorder

\begin{tabular}{|c|c|c|c|c|c|c|}
\hline Patient & $\begin{array}{l}\text { Age at } \\
\text { onset, } \\
\text { y/sex }\end{array}$ & Initial symptoms & Clinical course & Autoantibodies & Response to treatments & Reference \\
\hline $\begin{array}{l}\text { Present } \\
\text { case }\end{array}$ & $49 / M$ & Taste disorder & $\begin{array}{l}\text { Weakness of the upper limbs at } \\
\text { age of } 55 \\
\text { Mechanical ventilation and tube } \\
\text { feeding at age of } 58\end{array}$ & $(-)$ & No response to IVIG & \\
\hline 1 & $42 / \mathrm{M}$ & $\begin{array}{l}\text { Taste disorder } \\
\text { Perioral paresthesia and } \\
\text { numbness }\end{array}$ & $\begin{array}{l}\text { Weakness of the neck and shoulder } \\
\text { girdles at the age of } 50 \\
\text { Tube feeding at the age } \\
\text { of } 51 \\
\text { Died at the age of } 52 \text { due to } \\
\text { pulmonary embolism }\end{array}$ & $\begin{array}{l}(+) \text {, Anti-sulfatide } \\
\text { antibody }\end{array}$ & $\begin{array}{l}\text { No response to PDN, } \\
A Z A \text { and MMF }\end{array}$ & {$[10]$} \\
\hline 2 & $63 / F$ & Facial paresthesia & NA & $(-)$ & \multirow{7}{*}{$\begin{array}{l}\text { A part of patients 2-8 } \\
\text { were treated } \\
\text { with IVIG, but none of } \\
\text { them responded } \\
\text { to the treatment. }\end{array}$} & [18] \\
\hline 3 & $44 / F$ & Facial paresthesia & NA & $(-)$ & & [18] \\
\hline 4 & $40 / \mathrm{M}$ & Dysarthria & NA & $(-)$ & & [18] \\
\hline 5 & $41 / M$ & $\begin{array}{l}\text { Facial paresthesia and } \\
\text { weakness }\end{array}$ & NA & $(-)$ & & [18] \\
\hline 6 & $62 / F$ & $\begin{array}{l}\text { Facial paresthesia and } \\
\text { weakness }\end{array}$ & NA & $(-)$ & & [18] \\
\hline 7 & $50 / F$ & $\begin{array}{l}\text { Facial and upper limbs' } \\
\text { paresthesia and weakness }\end{array}$ & NA & $(-)$ & & [18] \\
\hline 8 & $51 / \mathrm{M}$ & $\begin{array}{l}\text { Facial paresthesia and } \\
\text { weakness } \\
\text { Weakness of upper limbs }\end{array}$ & NA & $(-)$ & & [18] \\
\hline
\end{tabular}


Approximately 50 patients with FOSMN have been described in the literature to date $[10,11,18]$, with 8 of them showing taste disturbance (Table 1). Most patients with taste disorder developed taste disturbance during the course of the disease. However, Vucic et al. described a 42-year-old man (patient 1 in Table 1) who developed taste disturbance with perioral sensory disturbance as an initial symptom. He was positive for anti-sulfatide antibody; however, he did not respond to immunotherapies, including prednisone, azathioprine, and mycophenolate mofetil. Contrastingly, our patient developed taste disturbance as the sole initial symptom with other manifestations developing more than 4 years after the onset of taste disorder. Although our patient did not respond to IVIG, he was alive without tube feeding or mechanical ventilation for over 8 years, which is similar to the case of a patient in a report by Vucic et al. [10]. Except for taste disturbance, the clinical characteristics of FOSMN with taste disorder were not markedly different from those without taste disorder.

Similar to patients with FOSMN who have taste disorder, a recent study reported changes in taste perception in patients with ALS who have dysphagia; among 32 patients, 8 of $11(73 \%)$ with an enteral tube and 5 of 21 (29\%) without an enteral tube complained of taste disturbance [9]. This result indicates that many patients with ALS may develop taste abnormalities. However, to our knowledge, there have been no reports of patients with ALS developing taste disorder as the initial manifestation of the disease.

In patients with neurodegenerative diseases, a taste disorder might be due to dysfunction of the gustatory tract, which consists of the facial nerve in the anterior two-thirds and the glossopharyngeal nerve in the posterior third of the tongue, the nucleus of the solitary tract, the thalamus, and the primary gustatory cortex. Brainstem pathologies seem to differ between patients with FOSMN and those with ALS. Autopsy studies examining patients with FOSMN have revealed neuronal loss and reactive astrocytosis with TDP-43 inclusions in the motor and sensory nuclei of the trigeminal and facial nerves, dorsal motor nucleus of the vagal nerve, nucleus ambiguous, nucleus of the solitary tract, and hypoglossal nerve [13-15]. On the other hand, TDP-43 pathologic involvement of cortical and subcortical white matter is rare [13, 15]. Neuronal loss and gliosis are not apparent in the thalamus, although deposition of TDP-43 can be detected similarly to sensory and motor nuclei in the brainstem [15]. These findings indicate that taste disturbance in patients with FOSMN might result from impairment of the solitary nucleus. Contrastingly, the brainstem pathology of ALS is characterized by neuronal loss and reactive astrocytosis with TDP-43 pathology in the motor nuclei of the trigeminal and facial nerves, dorsal motor nucleus of the vagal nerve, and nucleus of the hypoglossal nerve. TDP-43 deposition in the solitary nucleus is rare in ALS [19], and loss of the solitary nucleus was reported in only one Japanese ALS patient with fused in sarcoma gene mutation [20]. Given the rare involvement of the solitary nucleus in ALS, brain degeneration in FOSMN probably involves a different mechanism.

\section{Conclusions}

For the first time in the literature, we describe a patient with FOSMN who developed taste disturbance as the sole initial manifestation of the disease. In addition to somatosensory and/or motor dysfunction, taste disturbance can be an initial symptom in patients with FOSMN.

\section{Abbreviations}

ALS: amyotrophic lateral sclerosis; FOSMN: facial onset sensory and motor neuronopathy; IVIG: intravenous immunoglobulin; MRI: magnetic resonance imaging; TDP-43: TAR DNA-binding protein 43

\section{Acknowledgements \\ None.}

Authors' contributions

$\mathrm{NO}$ and JN contributed equally to this work. NO, JN, MK, KY, and YS contributed to data collection and interpretation. NO wrote the initial draft of the manuscript. MK assisted in the preparation of the manuscript. JN, KY and YS reviewed the manuscript. The authors read and approved the final manuscript.

\section{Funding}

None

Availability of data and materials

All data generated or analyzed during this study are included in this published article.

Ethics approval and consent to participate

All authors' institutions did not require ethical approval for publication of a single case report.

\section{Consent for publication}

Written informed consent was obtained from the patient for publication of this case report and any accompanying images. A copy of the written consent is available for review by the Editor of this journal.

\section{Competing interests}

None.

\section{Author details}

${ }^{1}$ Department of Medicine (Neurology and Rheumatology), Shinshu University School of Medicine, Matsumoto, Japan. ²Division of Neurogenetics, Department of Brain Disease Research, Shinshu University School of Medicine, 3-1-1 Asahi, Matsumoto 390-8621, Japan. ${ }^{3}$ Institute for Biomedical Sciences, Shinshu University, Matsumoto, Japan.

Received: 27 December 2019 Accepted: 10 February 2020 Received: 27 December 2019 Accepted: 10 Frents

\section{References}

1. Boesveldt S, Lindau ST, McClintock MK, Hummel T, Lundstrom JN. Gustatory and olfactory dysfunction in older adults: a national probability study. Rhinology. 2011:49:324-30

2. Hoffman HJ, Ishii EK, MacTurk RH. Age-related changes in the prevalence of smell/taste problems among the United States adult population. Results of the 1994 disability supplement to the National Health Interview Survey (NHIS). Ann N Y Acad Sci. 1998;855:716-22. 
3. Vennemann MM, Hummel T, Berger K. The association between smoking and smell and taste impairment in the general population. J Neurol. 2008;255:1121-6.

4. Liu G, Zong G, Doty RL, Sun Q. Prevalence and risk factors of taste and smell impairment in a nationwide representative sample of the US population: a cross-sectional study. BMJ Open. 2016;6:e013246.

5. Rawal S, Hoffman HJ, Bainbridge KE, Huedo-Medina TB, Duffy VB. Prevalence and risk factors of self-reported smell and taste alterations: results from the 2011-2012 US National Health and nutrition examination survey (NHANES). Chem Senses. 2016:41:69-76.

6. Syed Q, Hendler KT, Koncilja K. The impact of aging and medical status on dysgeusia. Am J Med. 2016;129:753.e1-6.

7. Hausser-Hauw C, Bancaud J. Gustatory hallucinations in epileptic seizures. Electrophysiological, clinical and anatomical correlates. Brain. 1987;110:339-59.

8. Steinbach S, Hundt W, Vaitl A, Heinrich P, Förster S, Bürger K, et al. Taste in mild cognitive impairment and Alzheimer's disease. J Neurol. 2010;257:238-46.

9. Tarlarini C, Greco LC, Lizio A, Gerardi F, Sansone VA, Lunetta C. Taste changes in amyotrophic lateral sclerosis and effects on quality of life. Neurol Sci. 2019:40:399-404.

10. Vucic S, Tian D, Chong PS, Cudkowicz ME, Hedley-Whyte ET, Cros D. Facial onset sensory and motor neuronopathy (FOSMN syndrome): a novel syndrome in neurology. Brain. 2006;129:3384-90.

11. Vucic S, Stein TD, Hedley-Whyte ET, Reddel SR, Tisch S, Kotschet K, et al. FOSMN syndrome: novel insight into disease pathophysiology. Neurology. 2012;79:73-9.

12. Zheng $\mathrm{Q}$, Chu L, Tan L, Zhang H. Facial onset sensory and motor neuronopathy. Neurol Sci. 2016;37:1905-9.

13. Sonoda K, Sasaki K, Tateishi T, Yamasaki R, Hayashi S, Sakae N, et al. TAR DNA-binding protein 43 pathology in a case clinically diagnosed with facialonset sensory and motor neuronopathy syndrome: an autopsied case report and a review of the literature. J Neurol Sci. 2013;332:148-53.

14. Ziso B, Williams TL, Walters RJ, Jaiser SR, Attems J, Wieshmann UC, et al. Facial onset sensory and motor neuronopathy: further evidence for a TDP43 proteinopathy. Case Rep Neurol. 2015;7:95-100.

15. Rossor AM, Jaunmuktane Z, Rossor MN, Hoti G, Reilly MM. TDP43 pathology in the brain, spinal cord, and dorsal root ganglia of a patient with FOSMN. Neurology. 2019;92:e951-6.

16. Kimura J. Electrically elicited blink reflex in diagnosis of multiple sclerosis. Review of 260 patients over a seven-year period. Brain. 1975;98:413-26.

17. Chéruel F, Jarlier $M$, Sancho-Garnier $H$. Effect of cigarette smoke on gustatory sensitivity, evaluation of the deficit and of the recovery timecourse after smoking cessation. Tob Induc Dis. 2017;15:15.

18. Pinto W, Naylor FGM, Chieia MAT, de Souza PVS, Oliveira ASB. New findings in facial-onset sensory and motor neuronopathy (FOSMN) syndrome. Rev Neurol (Paris). 2019;175:238-46.

19. Nishihira Y, Tan CF, Onodera O, Toyoshima Y, Yamada M, Morita T, et al. Sporadic amyotrophic lateral sclerosis: two pathological patterns shown by analysis of distribution of TDP-43-immunoreactive neuronal and glial cytoplasmic inclusions. Acta Neuropathol. 2008;116:169-82.

20. Tateishi T, Hokonohara T, Yamasaki R, Miura S, Kikuchi H, Iwaki A, et al. Multiple system degeneration with basophilic inclusions in Japanese ALS patients with FUS mutation. Acta Neuropathol. 2010;119:355-64.

\section{Publisher's Note}

Springer Nature remains neutral with regard to jurisdictional claims in published maps and institutional affiliations.

Ready to submit your research? Choose BMC and benefit from:

- fast, convenient online submission

- thorough peer review by experienced researchers in your field

- rapid publication on acceptance

- support for research data, including large and complex data types

- gold Open Access which fosters wider collaboration and increased citations

- maximum visibility for your research: over $100 \mathrm{M}$ website views per year

At $\mathrm{BMC}$, research is always in progress.

Learn more biomedcentral.com/submissions 